\title{
Lack of vasoactive intestinal peptide reduces testosterone levels and reproductive aging in mouse testis
}

\author{
Arnaud Lacombe ${ }^{1,4}$, Vincent Lelievre ${ }^{2,5}$, Charles E Roselli ${ }^{3}$, Jean-Marc Muller ${ }^{4}$, James A Waschek ${ }^{5}$ and \\ Eric Vilain ${ }^{1}$ \\ ${ }^{1}$ Departments of Human Genetics, Pediatrics, and Urology, David Geffen School of Medicine at UCLA, Gonda Center, University of California, Room 6357, 695 \\ Charles Young Drive South, Los Angeles, California 90095-7088, USA \\ ${ }^{2}$ Institut National de la Santé et de la Recherche Médicale U676, Hôpital Robert-Debré, 48 Boulevard Sérurier, F-75019 Paris, France \\ ${ }^{3}$ Department of Physiology and Pharmacology L334, Oregon Health \& Science University, 3181 Southwest Sam Jackson Park Road, Portland, Oregon 97201- \\ 3098, USA \\ ${ }^{4}$ Institut de Physiologie et Biologie Cellulaires, Centre National de la Recherche Scientifique-Unité Mixte de Recherche, 6187 Pôle Biologie Santé, 40 Avenue du \\ Recteur Pineau, 86022 Poitiers, France \\ ${ }^{5}$ Mental Retardation Research Center, University of California, Neurosciences Research Building, 655 Charles Young Drive South, Los Angeles, California \\ 90095-7088, USA \\ (Requests for offprints should be addressed to E Vilain; Email: evilain@ucla.edu)
}

\begin{abstract}
The neuropeptides vasoactive intestinal peptide (VIP) and pituitary adenylate cyclase-activating polypeptide have long been considered as putative regulators of testicular functions. In vitro evidence suggests that VIP could play an important role in testosterone biosynthesis. However, the endogenous role of VIP on testicular functions remained to be demonstrated. In C57BL/6 mice exhibiting a complete disruption of the VIP gene, we first observed here that serum testosterone levels were lower than those of WT littermates. At the age of 4 months, this phenotype was accompanied with a reduction of expression of StAR and $3-\beta$-hydroxysteroid dehydrogenase $(3 \beta-\mathrm{HSD})$ in the testis. In addition, serum levels of FSH but not $\mathrm{LH}$ were reduced in young knock-out (KO) males. Testicular anatomy also revealed a higher percentage of degenerated
\end{abstract}

seminiferous tubules in the 4-month-old VIP KO animals when compared with WT. In 15-month-old animals, control males showed typical testicular aging, including a severe degeneration of seminiferous tubules, a dramatic decrease in serum levels of testosterone, and a reduction in StAR and $3 \beta$-HSD gene expression. In age-matching VIP $\mathrm{KO}$ males, the levels of serum testosterone and steroidogenic enzymes were still very low. Interestingly, in contrast to that observed in young mice, testicular degeneration at 15 months was significantly less severe in VIP KO than WT mice. All together, these results suggest that 1) VIP is an important factor for regulating testosterone biosynthesis and FSH secretion and 2) VIP may influence testicular aging.

Journal of Endocrinology (2007) 194, 153-160

\section{Introduction}

Vasoactive intestinal peptide (VIP) is a 28 -amino acid peptide, originally isolated from porcine duodenum (Said \& Mutt 1970). Together with its analog pituitary adenylate cyclaseactivating polypeptide (PACAP), they belong to the glucagon/secretin family. VIP expression is almost ubiquitous since it is produced and secreted not only in the intestinal tract, but also in specific brain structures (including hypothalamic, facial motor, and suprachiasmatic nuclei) and many other peripheral tissues (Said \& Mutt 1970, Said \& Rosenberg 1976, Loren et al. 1979, Nagy et al. 1988, Koves et al. 1990). Structurally, VIP shares homologies with PACAP and other related peptides, such as peptide histidine isoleucine (PHI). They also share common G-protein-coupled receptors (called VPAC1: VIP/PACAP receptor type 1 and VPAC2:
VIP/PACAP receptor type 2) that mediate numerous similar effects (Vaudry et al. 2000). However, this functional overlap is not complete, since a third receptor, called PAC1 (PACAP type 1 receptor), known to selectively prefer PACAP to VIP, exists and may play a key role in preventing VIP from fully compensating for the loss of PACAP.

Among many other biological activities, VIP is a wellknown neurotropic peptide with neuroprotective properties (Brenneman et al. 1998). During the last decade, it has also been suggested that VIP could act as a neuroendocrine hormone (Lam 1991). Accordingly, studies have revealed a physiological role for VIP in reproductive functions. In particular, direct injection of VIP, alone or in combination with acetylcholine, into corpus cavernosum, has been used clinically first in adult rats, then in humans suffering from functional impotence (Suh et al. 1995). Studies of the 
molecular and cellular signaling pathway mediating VIP action revealed that VIP, through VPAC1 receptors, stimulated nitric oxide synthase activity in order to initiate penile erection, leading to a more potent, and possibly safer medication: the Sildenafil, universally known as Viagra.

VIP also acts directly on the testis. In WT males, VIP is, at least in cats, released in the vicinity of Leydig cell nests by specific VIPergic fibers representing the most abundant subpopulation of the inferior spermatic nerve (Suburo et al. 2002). In vitro treatment of cultured Leydig cells with VIP results in dose-dependent increases in the production of testosterone, progesterone, and pregnenolone (Kasson et al. 1986) suggesting a direct stimulatory effect of VIP on Leydig cells. This effect appeared to be specific, since picomolar concentrations of VIP are sufficient to induce testosterone production by dispersed fetal Leydig cells isolated from embryonic rat testes (El-Gehani et al. 1998a). To mediate its physiological actions, VIP interacts with polyvalent VPAC2 receptors that were specifically detected as early as E15.5 in rat fetal testes by RT-PCR analysis (El-Gehani et al. 1998a) and in the adult testis by in situ hybridization (Krempels et al. 1995). VPAC2 null-mutant mice are fertile as young adults, but, as they age, exhibit hypospermia and decreased fertility which is accompanied with diffuse seminiferous tubular degeneration (Asnicar et al. 2002).

Given that VIP stimulates testosterone production in vitro, we hypothesized that this neuropeptide could be an important endogenous regulator of testosterone production, in vivo. Therefore, we hypothesized that VIP-null males would display a severe testicular phenotype including deficiencies in fertility as well as in androgen synthesis. In the present article, we evaluated the steroidogenic capacity and morphology in young and old VIP-deficient mice and WT controls and compared these data with what we previously observed in PACAP null mice (Lacombe et al. 2006). We show that VIP-deficient males displayed lower serum concentrations of follicle-stimulating hormone (FSH) and a dramatic decrease in the serum concentrations of testosterone when compared with WT. They also displayed early signs of testicular degeneration. Finally, testicular aging was delayed in the old VIP KO, but the degree of conservation of the testicular structure was less than what we found previously in PACAP $^{-1-}$ mice. This study also demonstrated that aged VIP and PACAP null mice exhibited different reproductive phenotypes, suggesting that these two peptides cannot compensate for each other, but rather cooperate, to regulate testicular function.

\section{Materials and Methods}

\section{Animals}

VIP-deficient male mice backcrossed for at least six generations in a C57BL/6 background were used in the study. They were housed and fed ad libitum in a conventional animal facility. Wild-type age-matched controls from an identical genetic background were analyzed. These controls were generated by breeding a male $\mathrm{VIP}^{+/-}$and a female $\mathrm{VIP}^{+1-}$, whereas the knockout animals were generated by breeding either a male $\mathrm{VIP}^{+/-}$and a female $\mathrm{VIP}^{+/-}$, or a male VIP ${ }^{-\prime-}$ and a female $\mathrm{VIP}^{-\prime-}$.

\section{Blood collection and hormones measurements}

Mice were anesthetized with isoflurane. Blood was then collected by heart puncture, clotted at $4{ }^{\circ} \mathrm{C}$ overnight, then centrifuged for $10 \mathrm{~min}$ at $10000 \mathrm{~g}$ at $4{ }^{\circ} \mathrm{C}$ in order to separate the serum from the rest of the cells. The serum was stored at $-20{ }^{\circ} \mathrm{C}$ until further analysis. Serum testosterone concentrations were analyzed by RIA after ether extraction according to previously published methodology (Resko et al. 1973). Serum concentrations of luteinizing hormone $(\mathrm{LH})$ and FSH levels were measured by the National Hormone and Peptide Program (Dr A F Parlow, University of California, Los Angeles, CA, USA) using rat $\mathrm{LH}$ and FSH RIA kits. The sensitivity for the $\mathrm{LH}$ assay was $0.3 \mathrm{ng} / \mathrm{ml}$. The sensitivity for the FSH assay was $2 \cdot 0 \mathrm{ng} / \mathrm{ml}$ (www.healthsystem.virginia.edu_internet_crr_methodspage.cfm). In all the groups, the $n$ value (comprised between 6 and 15) was powerful enough to detect moderate effect sizes. For example, in the group with the largest variations (15-month-old $\left.\mathrm{VIP}^{-\prime-}\right)$, compared with 4-month-old $\mathrm{VIP}^{-\prime-}$, there would be sufficient power with nine mice per group to detect differences of $0.9 \mathrm{ng} / \mathrm{ml}$ or greater than $80 \%$ of the time. Values less than $0.9 \mathrm{ng} / \mathrm{ml}$ would have little biological significance. Therefore, we can be reasonably assured that we did not miss a biologically meaningful difference.

\section{Histology}

Testes from wild type (WT) and VIP KO mice were weighed and fixed in $4 \%$ paraformaldehyde (PFA) for $48 \mathrm{~h}$ at $4{ }^{\circ} \mathrm{C}$. Tissues were then embedded in paraffin prior to sectioning. Mounted sections $(6 \mu \mathrm{m})$ were stained with hematoxylin-eosin, under standard protocols. Two different populations of seminiferous tubules were discriminated: 'healthy' if the general architecture showed normal spermatogenesis with all the layers of spermatogenic cells associated with each of the XII stages of spermatogenesis, or 'degenerated' if they showed depletion of all or some of germ cell layers usually associated with vacuolization within the seminiferous tubule. This quantification was performed blindly and by two independent investigators.

\section{Quantitative RT-PCR}

The left testis from each mouse was weighed, quick frozen in liquid nitrogen. Total RNA from the different tissue samples was isolated with TriZol solution according to the manufacturer's procedures and subjected to DNaseI treatment for $30 \mathrm{~min}$ at $37^{\circ} \mathrm{C}$ to remove any genomic DNA contamination. DNA-free RNA was reverse-transcribed into cDNA according to the 
manufacturer's instructions (Iscript kit from Bio-Rad). Two independent real-time quantitative PCR were performed with individual samples run in triplicate, using SybrGreen PCR supermix from Bio-Rad in combination with primers sets designed as previously described (DiCicco-Bloom et al. 2004). PCR amplifications were set for 45 cycles using three-step program $\left(96^{\circ} \mathrm{C}\right.$ for $20 \mathrm{~s}, 62^{\circ} \mathrm{C}$ for $20 \mathrm{~s}$, and $72{ }^{\circ} \mathrm{C}$ for $20 \mathrm{~s}$ ) prior to melting curve assay to eliminate false positive results due to amplification of additional amplicons or formation of primer dimers. Using the following primer sets for amplification of StAR gene (5'-TTCTCAACTGGAAGCAACACT- $3^{\prime}$ and $5^{\prime}$-CTTCTGCATAGCCACCTCTC- $3^{\prime}$ ) and $3-\beta$-hydroxysteroid dehydrogenase $\left(3 \beta\right.$-HSD; $5^{\prime}$-GGATCATCAAGATGTTGGTGC- $3^{\prime}$ and $5^{\prime}$-TGGTTTCTGGTCGGAATACTT- $3^{\prime}$ ), we were able to selectively amplify DNA fragments of 75 and $90 \mathrm{pb}$ corresponding to the region 233-308 and 170-260 of the NCBI-published StAR and 33-HSD mouse sequences (Accession numbers NM_011485 and NM_008293) respectively. Quantification was performed using standard curves for both genes of interest and a housekeeping reference (GAPDH) made by serial dilution of RT control samples. Standardization of basal levels between samples was made possible using GAPDH as the housekeeping gene (DiCicco-Bloom et al. 2004). Gene expression levels were compared with each other as the differences between StAR:GAPDH or $3 \beta-H S D: G A P D H$ ratio. Specificity of gene amplification was validated by melting curves and sequencing of PCR products.

\section{Data evaluation and statistical analysis}

Results are expressed as mean \pm s.E.M. Two-way analyses of variance, using genotype (WT versus VIP KO) and age (4, 15 month-old) as comparison parameters, were performed using GraphPad Prism4 software (GraphPad Software Inc., San Diego, CA, USA). When the overall analysis was significant, multiple pairwise post hoc analyses using Student's $t$-tests and Bonferroni/Dunn adjustments were conducted to determine where the significant differences lay. The level of significance was set at $P<0 \cdot 05$.

\section{Results}

Absence of VIP is associated with very low testosterone levels in young adult male mice

In order to test whether the absence of VIP in mouse could affect normal testosterone production, we first measured the concentration of testosterone in serum collected from 4-month-old WT $(n=8)$ and VIP KO male mice $(n=8$; Fig. 1A). We observed a profound reduction $(P=0 \cdot 0046)$ in concentration of serum testosterone in VIP KO animals when compared with age-matched WT $(0 \cdot 16 \pm 0 \cdot 05$ vs $12 \cdot 65 \pm$ $3.8 \mathrm{ng} / \mathrm{ml}$ respectively). This was accompanied with a reduction of seminal vesicles weight, organs known to be under the direct control of testosterone for their development $(0 \cdot 39 \pm 0 \cdot 05 \mathrm{~g}$ for WT, $n=19$ and $0 \cdot 25 \pm 0 \cdot 01 \mathrm{~g}$ for VIP KO, $n=9, P<0 \cdot 001)$.

To address the question of the origin of this effect, we further investigated expression levels of two key components of the steroidogenic pathway. First, we measured StAR mRNA expression, a protein which can activate the transport of cholesterol from cytoplasm into the inner membrane of mitochondria, which is known to be the limiting factor in substrate concentration for steroidogenesis (Stocco 2001). We also measured 3 $\beta-H S D$ mRNA expression, an enzyme critical for testosterone synthesis. In VIP KO animals, both StAR mRNA (Fig. 1B, 2-4-fold decrease, $P=0 \cdot 0092$ ) and $3 \beta$-HSD (Fig. 1C, 1.62-fold decrease, $P=0.0026$ ) were significantly lower when compared with WT.

Testosterone levels, reduced in aging $W T$ males, remain low and constant in aging VIP $\mathrm{KO}$ animals

We investigated the same parameters in 15-month-old animals to elucidate whether early reduction in testosterone could affect aging process in testis. In WT males, a dramatic decrease in the concentration of testosterone was observed between 4 and 15 months of age (26-fold, $P=0 \cdot 001$ ) similar to what was observed in our previous study using PACAP KO mice (Lacombe et al. 2006). In contrast, testosterone levels remained low and constant over the lifespan of VIP KO animals and matched the levels seen in aging wild-type mice (Fig. 1A). We further measured relative expression level of StAR and $3 \beta-H S D$ genes in the testis of these old animals, by quantitative real-time PCR. In WT animals, StAR expression (Fig. 1B) was significantly reduced at 15 months $(2 \cdot 7$-fold, $P=0 \cdot 0005$ ), but not $3 \beta-\mathrm{HSD}$ (Fig. 1C). In $\mathrm{VIP}^{-\prime-}$ mice, expression levels of StAR and $3 \beta-\mathrm{HSD}$ were low at both ages (Fig. 1B and C).

Differential reduction in gonadotropin levels in VIP KO animals when compared with WT

VIP action on pituitary LH and FSH secretion has long been controversial (Hammond et al. 1993, Sawangjaroen et al. 1997). LH and FSH could subsequently affect gonad development and functions, especially testicular steroidogenesis and spermatogenesis. Anatomical evidence indicates that gonadotropin-releasing hormone cells in the hypothalamus are innervated by VIP-ergic neurons of the suprachiasmatic nucleus (van der Beek et al. 1993). The day/night rhythm that controls the sleep/activity is impaired in VIP KO mice (Colwell et al. 1973), raising the question whether the pituitary gonadotroph function was also perturbed. Therefore, we measured serum concentrations of pituitary $\mathrm{LH}$ and FSH (Fig. 2A and B). There was no significant difference in LH levels in WT versus $\mathrm{KO}$ at 4 or 15 months of age (Fig. 2A). However, we found significantly lower concentrations of serum FSH in 4-month-old VIP KO animals when compared with WT (Fig. 2B, 83.44 $\pm 3.08 \mathrm{ng} / \mathrm{ml}$ for the 

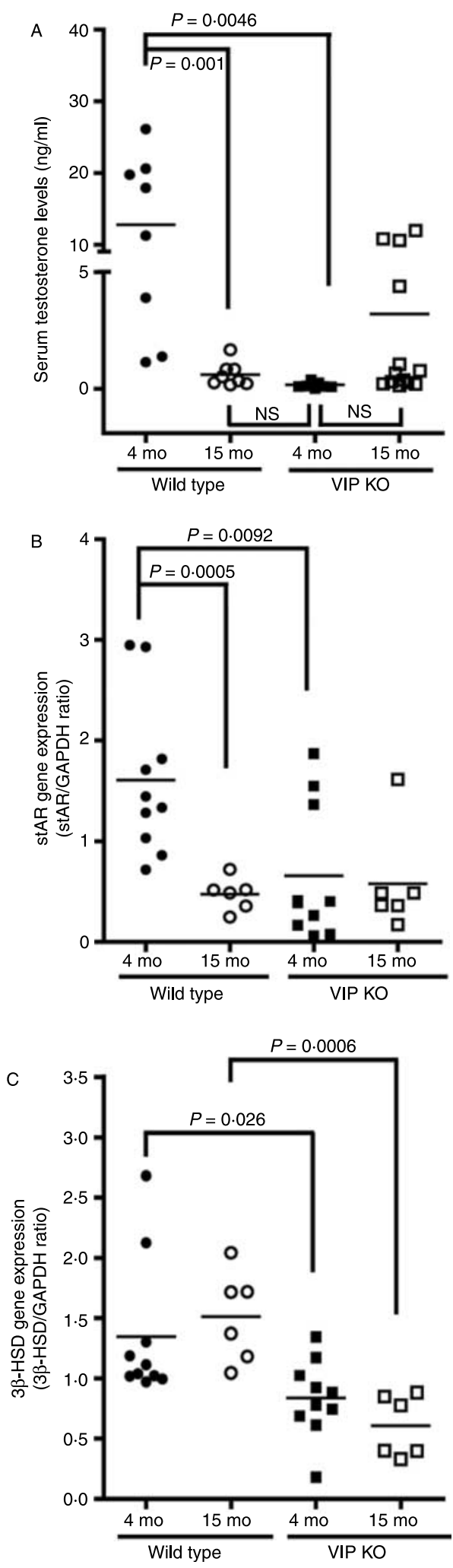

Journal of Endocrinology (2007) 194, 153-160 wild-type and $58 \pm 4.94 \mathrm{ng} / \mathrm{ml}$ for the VIP KO mice; $P=$ $0 \cdot 0001)$.

Testicular structure is impaired in young VIP mutants but better conserved in aged VIP KO when compared with WT controls

To determine whether the reduced testosterone production in VIP KO mice might affect the inner testicular structure and age-dependent degeneration, we studied the testicular structure of the knockout animals at 4 and 15 months of age.

Histopathological studies in testis revealed differences in testicular morphology between 4-month-old WT and VIP KO (Fig. 3A). Testis of VIP KO mice exhibited a significant increase in the percentage of degenerated seminiferous tubules (Fig. 3B, 4.14 $\pm 0 \cdot 85 \%$ degenerated tubules for the WT and $15 \cdot 23 \pm 3 \cdot 22 \%$ degenerated tubules for the VIP KO mice, $P=0 \cdot 0076$ ).

At 15 months, the structure of WT testis (Fig. 3A) displayed typical signs of aging: a severe depletion of germ cells, presence of vacuolizations, and a thin epithelium predominantly constituted of residual Sertoli cells (Fig. 3A). We found that $77 \%$ of all seminiferous tubules showed signs of degeneration in 15-month-old WT males. This represents a significant increase $(P=0 \cdot 0079)$ when compared with the 4-month-old WT males. These features were associated with a significant loss $(P=0 \cdot 0012)$ in the testis + epididymis

Figure 1 Comparison of testosterone and steroidogenesis levels during aging between WT and VIP KO animals. (A) Serum testosterone levels during aging in WT and VIP KO males. Between $4(n=8)$ and 15 months $(n=8)$, serum testosterone decreased dramatically in wild-type animals, while levels remain low and constant in VIP KO mice $(n=9$ for 4-month-old and $n=15$ for 15 -month-old animals), during the same period of time. Two-way ANOVA followed by ad hoc Bonferroni post-test showed that differences between genotype groups at 4 month of age were statistically significant with a $P<0 \cdot 01$. Further pairwise comparisons using $t$-test calculated $P$ values indicated on the graph. (B and C) Expression profile of StAR and $3 \beta-\mathrm{HSD}$ during aging. Testes of both WT ( $n=5$ for 4 - and $n=3$ for 15 -month-old animal) and VIP $\mathrm{KO}$ ( $n=6$ for 4 - and $n=5$ for 15 -month-old animal) were dissected and prepared as described in Materials and Methods. Quantitative RT-PCR experiments revealed that the level of expression of StAR (B) is significantly reduced in WT animals when aging, but remained low and constant in $\mathrm{KO}$ animals. Similar experiments performed with $3 \beta-\mathrm{HSD}(\mathrm{C})$ revealed no significant difference in expression levels in WT animals, between 4 and 15 months. In VIP KO mice, similar to that of StAR, the level of expression of $3 \beta-H S D$ was low and constant over the time. Data normalization was performed using GAPDH as the housekeeping gene. Data presented in the graph are the results of the two separate experiments and are expressed as a ratio of specific PCR products over the amount of the housekeeping gene GAPDH. Two-way ANOVA followed by ad hoc Bonferroni post-test showed that differences between genotype groups at 4 month of age were statistically significant with a $P<0 \cdot 01, P<0 \cdot 01$, and $P<0 \cdot 05$ for testosterone, StAR, and $3 \beta-\mathrm{HSD}$ respectively, while these differences were significant at 15 month of age only for $3 \beta-H S D$ with $P<0 \cdot 01$. Further pairwise comparisons using $t$-test calculated $P$ values indicated on the graph. NS, non-significant. 

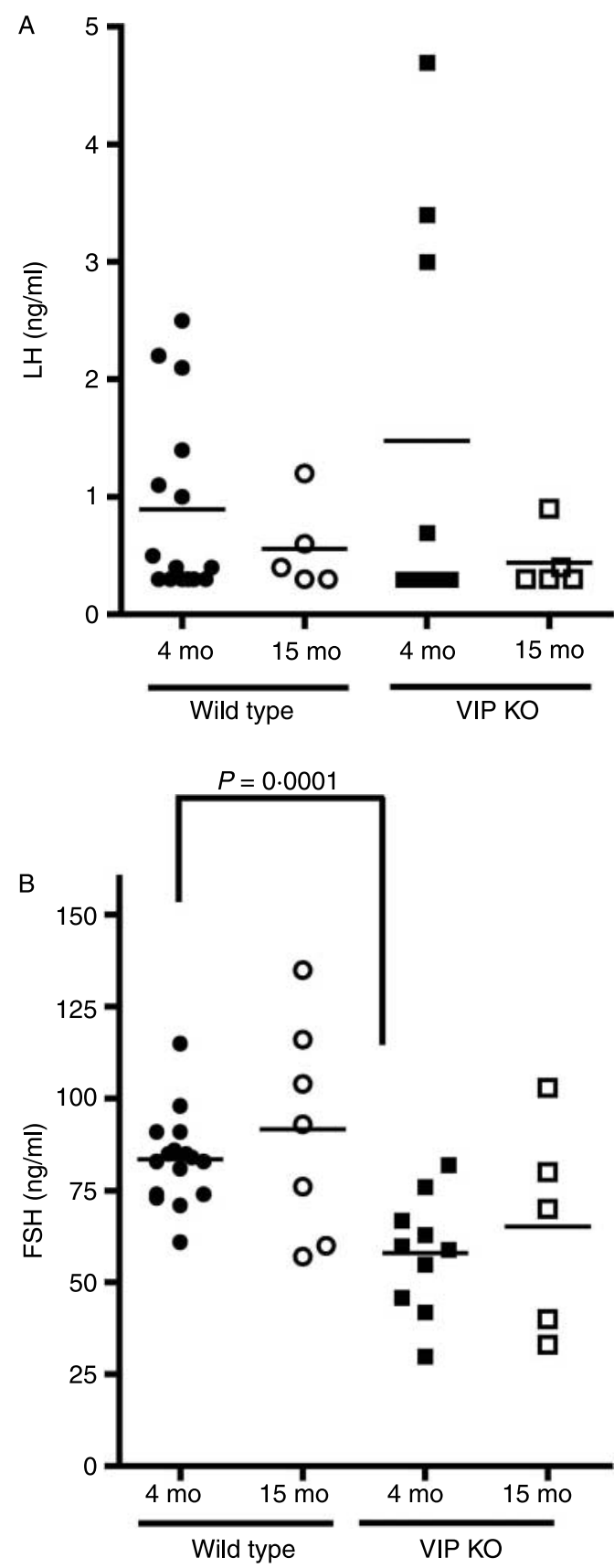

Figure 2 Comparison of serum $\mathrm{LH}$ (A) and serum FSH (B) levels during aging in WT and VIP KO males. Levels of LH and FSH hormones were assayed as described in Materials and Methods. For LH: $n=15$ WT and $n=9$ VIP KO at 4-month-old males, and $n=5$ WT and $n=5$ VIP KO at 15-month-old males. For FSH: $n=16$ WT and $n=10$ VIP KO at 4-month-old males, and $n=7$ WT and $n=5$ VIP KO at 15-month-old males. Two-way ANOVA followed by ad hoc Bonferroni post-test showed that differences between genotype groups at 4 month of age were statistically significant with a $P<$ 0.01 for FSH. Further pairwise comparisons using $t$-test calculated $P$ values indicated on the graph. weight (Fig. 3C). In VIP KO animals, at the same age, the whole architecture of the testis was better preserved (Fig. 3A). We recorded $46 \cdot 5 \%$ of degenerating seminiferous tubules (Fig. 3B). The conservation of the structural integrity of the VIP $\mathrm{KO}$ testis was associated with no significant difference in weight of whole testis, remaining constant from 4 to 15 months (Fig. 3C).

\section{Discussion}

\section{VIP action on testicular steroidogenesis}

We first observed that the VIP KO mice displayed a dramatic decrease in concentration of serum testosterone when compared with WT. This phenomenon was associated with a decrease in mRNA expression of two key components of the testosterone biosynthesis pathway, i.e. StAR and 3 $\beta$-HSD. This result is consistent with previous in vitro studies showing that VIP stimulates steroidogenesis in rat Leydig cell culture assays (El-Gehani et al. 1998a). However, reports from the same group suggest that VIP/ PACAP action on testis is most likely preponderant during fetal testicular Leydig cell development, whereas pituitary $\mathrm{LH}$ becomes a constitutive component in the onset of steroidogenesis in adult life (El-Gehani et al. 1998b). This decrease of steroidogenesis may be more profound in VIP $\mathrm{KO}$ than in $\mathrm{PACAP}^{-/-}$since the testosterone level in the young VIP KO animals is even lower than the level found in the $\mathrm{PACAP}^{-/-}$mice (data not shown). As we already observed in PACAP ${ }^{-1-}$ mice, even if the testosterone is very low in the VIP KO, these animals are still fertile because they routinely breed in our colony.

The pituitary is under the negative feedback control of testosterone suggesting that in VIP KO mice, the overall function of pituitary might be affected by the decrease in testosterone levels. Moreover, testosterone was reported to stimulate FSH release (Padmanabhan et al. 2002). Indeed, we measured $\mathrm{LH}$ and FSH production by RIA and demonstrated that blood FSH concentrations were significant reduced in VIP null males. As we previously reported in our study with the PACAP $\mathrm{KO}$ mice, the fact that no difference in $\mathrm{LH}$ levels has been observed raises the question of the origin of the dysfunction. Like PACAP, VIP can regulate gonadotropin release and secretion, but could also act directly on Leydig cells to regulate testosterone biosynthesis, suggesting that it is a mixed dysfunction, both at the peripheral (testis) and central (pituitary) level.

Another putative key player in the whole hypothalamuspituitary axis function/secretion is the rhythmic activity of suprachiasmatic nucleus. It has been demonstrated that the dark-light circadian rhythm is damaged in VIP null mice (Colwell et al. 2003), suggesting that rhythmic secretion of gonadotropins might be perturbed in VIP KO mice. 
A

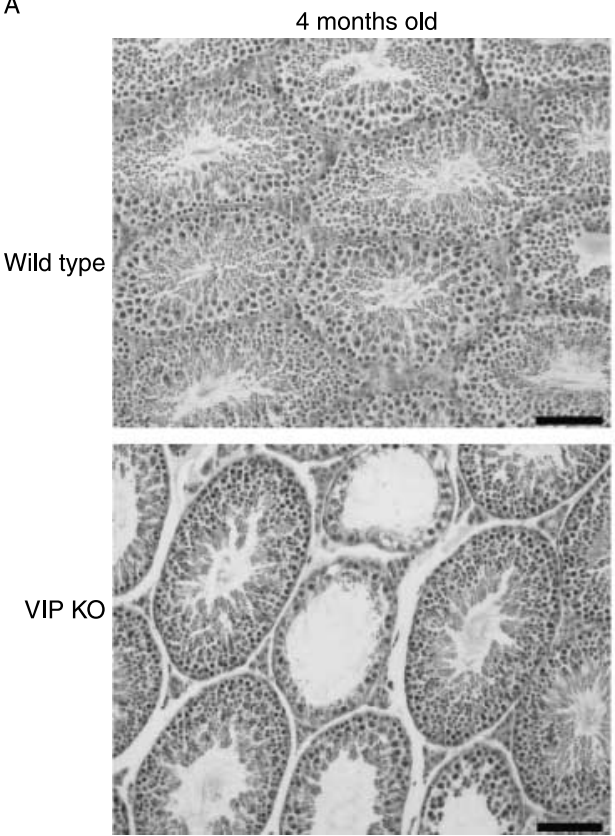

B

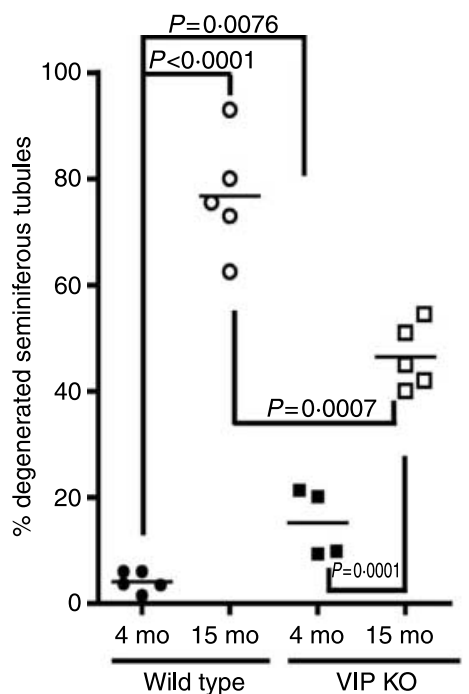

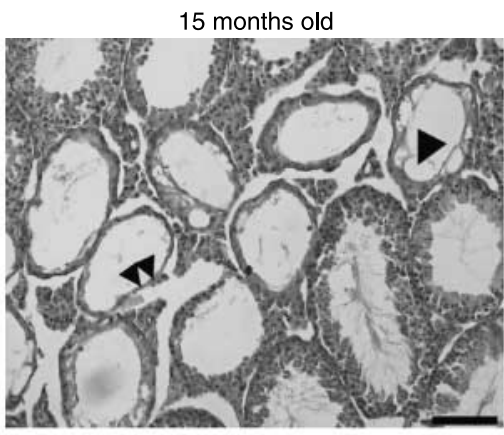

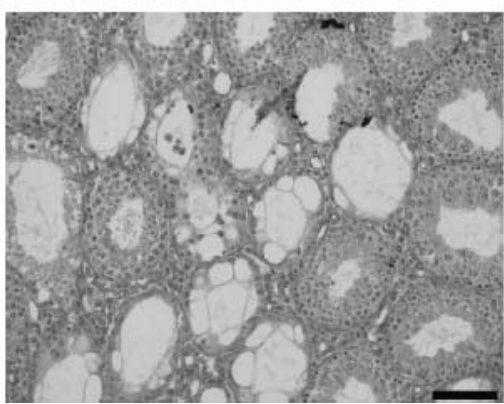

C

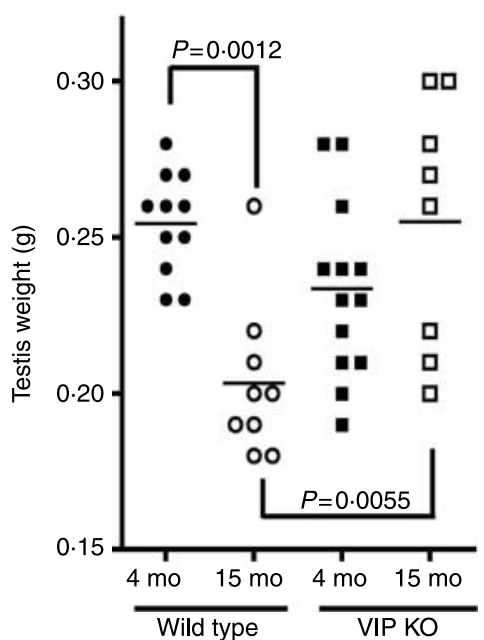

Figure 3 Histopathology of 4- and 15-month-old WT and VIP-deficient mice testes. (A) Testes of both WT at 4 months $(n=5)$ and 15 months $(n=5)$ and VIP-deficient mice at 4 months $(n=4)$ and 15 months $(n=8)$ were fixed in $4 \%$ PFA and embedded into paraffin. Mounted sections $(6 \mu \mathrm{m})$ were deparaffinized, rehydrated, and stained with hematoxylin-eosin (Scale bar $=100 \mu \mathrm{m})$. Double arrowhead shows the depletion of cells often observed into the seminiferous tubules of old WT animals and black arrow points to the vacuolizations also found at high frequency around the seminiferous tubules of these animals. (B) Rate of seminiferous tubules degeneration. On whole testes sections stained with hematoxylin-eosin ( $n$ between 4 and 8 for each group), two populations of seminiferous tubules were scored in a blind study as 'healthy' if the general architecture displayed normal spermatogenesis, or as 'degenerated' if they showed either depletion of one or more layers of the expected stage specific germ cells, or vacuolizations, or both. Results are presented as the percentage of degenerated seminiferous tubules per testicular section. (C) Testis weight. Testes and epididymis were dissected out and weighed in both WT and VIP-deficient mice at 4 months old ( $n=11$ and 10 respectively), and also at 15 months old ( $n=9$ and $n=7)$. Two-way ANOVA followed by ad hoc Bonferroni post-test showed that the differences between genotype groups at 4 month of age were statistically significant with a $P<0 \cdot 01$ for degenerated tubules; whereas both experiments showed significant differences at 15 months of age with $P<0 \cdot 001$. Further pairwise comparisons using $t$-test calculated $P$ values indicated on the graph. 
Altogether, these data strongly favor the idea that the lack of VIP affects both pituitary and testicular functions.

\section{VIP null males show a significant reduction in age-related testicular degeneration}

The second aim of the present study was to analyze longterm effects of the VIP-dependent reduced testosterone levels on testicular morphology. Like that observed in PACAP null male mice (Lacombe et al. 2006), we observed a significant protection against testicular aging in older VIP KO mice when compared with age-matched WT males. However, the degree of protection induced by a lack of VIP was not as high as what we obtained in PACAP null males. At the age of 4 months, the VIP KO mice display very low testosterone and lower FSH levels when compared with WT. These two factors are essential for the maintenance of spermatogenesis (Simoni et al. 1999, Zhang et al. 2003). In situ hybridization studies indicated that the VIP receptor mRNA VPAC2 was localized in the seminiferous epithelium (Krempels et al. 1995). Indeed, one could hypothesize that VIP acts on Sertoli cells where the VPAC2 receptor is present. VIP's action could include the regulation of Sertoli cell protein secretion, such as inhibin, which in turn could inhibit FSH release from the pituitary.

Among its biological properties, VIP is a factor which could regulate the growth, proliferation, or differentiation of several cell types (Waschek 1995). It is possible that VIP could directly regulate such activities in testicular cells.

In conclusion, VIP null males showed an overall reduction in circulating concentrations of testosterone and FSH that probably impaired the general morphology of testicular seminiferous tubules in young males, but also reduced age-dependent degeneration of testis structure and function. The question of the precise mechanism by which VIP acts to induce steroidogenesis remains to be elucidated.

\section{Acknowledgements}

We are particularly thankful to Anne-Claire Coute for daily animal care, breeding setups, and taking care of the burden of weaning, tagging, genotyping, and updating animal records. This work was supported by the Société d'Andrologie de Langue Française. The authors declare that there is no conflict of interest that would prejudice the impartiality of this scientific work.

\section{References}

Asnicar MA, Koster A, Heiman ML, Tinsley F, Smith DP, Galbreath E, Fox N, Ma YL, Blum WF \& Hsiung HM 2002 Vasoactive intestinal polypeptide/pituitary adenylate cyclase-activating peptide receptor 2 deficiency in mice results in growth retardation and increased basal metabolic rate. Endocrinology 143 3994-4006. van der Beek EM, Wiegant VM, van der Donk HA, van den Hurk R \& Buijs RM 1993 Lesions of the suprachiasmatic nucleus indicate the presence of a direct vasoactive intestinal polypeptide-containing projection to gonadotrophin-releasing hormone neurons in the female rat. Journal of Neuroendocrinology 5 137-144.

Brenneman DE, Glazner G, Hill JM, Hauser J, Davidson A \& Gozes I 1998 VIP neurotrophism in the central nervous system: multiple effectors and identification of a femtomolar-acting neuroprotective peptide. Annals of the New York Academy of Sciences 865 207-212.

Colwell CS, Michel S, Itri J, Rodriguez W, Tam J, Lelievre V, Hu Z, Liu X \& Waschek JA 2003 Disrupted circadian rhythms in VIP- and PHI-deficient mice. American Journal of Physiology. Regulatory, Integrative and Comparative Physiology 285 R939-R949.

DiCicco-Bloom E, Lelievre V, Zhou X, Rodriguez W, Tam J \& Waschek JA 2004 Embryonic expression and multifunctional actions of the natriuretic peptides and receptors in the developing nervous system. Developmental Biology 271 161-175.

El-Gehani F, Tena-Sempere M \& Huhtaniemi I 1998a Vasoactive intestinal peptide stimulates testosterone production by cultured fetal rat testicular cells. Molecular and Cellular Endocrinology 140 175-178.

El-Gehani F, Zhang FP, Pakarinen P, Rannikko A \& Huhtaniemi I 19986 Gonadotropin-independent regulation of steroidogenesis in the fetal rat testis. Biology of Reproduction 58 116-123.

Hammond PJ, Talbot K, Chapman R, Ghatei MA \& Bloom SR 1993 Vasoactive intestinal peptide, but not pituitary adenylate cyclase-activating peptide, modulates the responsiveness of the gonadotroph to LHRH in man. Journal of Endocrinology 137 529-532.

Kasson BG, Lim P \& Hsueh AJ 1986 Vasoactive intestinal peptide stimulates androgen biosynthesis by cultured neonatal testicular cells. Molecular and Cellular Endocrinology 48 21-29.

Koves K, Gottschall PE, Gorcs T, Scammell JG \& Arimura A 1990 Presence of immunoreactive vasoactive intestinal polypeptide in anterior pituitary of normal male and long term estrogen-treated female rats: a light microscopic immunohistochemical study. Endocrinology 126 1756-1763.

Krempels K, Usdin TB, Harta G \& Mezey E 1995 PACAP acts through VIP type 2 receptors in the rat testis. Neuropeptides 29 315-320.

Lacombe A, Lelievre V, Roselli CE, Salameh W, Lue YH, Lawson G, Muller JM, Waschek JA \& Vilain E 2006 Delayed testicular aging in pituitary adenylate cyclase-activating peptide (PACAP) null mice. PNAS 103 3793-3798.

Lam KS 1991 Vasoactive intestinal peptide in the hypothalamus and pituitary. Neuroendocrinology $\mathbf{5 3}$ 45-51.

Loren I, Emson PC, Fahrenkrug J, Bjorklund A, Alumets J, Hakanson R \& Sundler F 1979 Distribution of vasoactive intestinal polypeptide in the rat and mouse brain. Neuroscience 4 1953-1976.

Nagy G, Mulchahey JJ \& Neill JD 1988 Autocrine control of prolactin secretion by vasoactive intestinal peptide. Endocrinology 122 364-366.

Padmanabhan V, Karsch FJ \& Lee JS 2002 Hypothalamic, pituitary and gonadal regulation of FSH. Reproduction Supplement 59 67-82.

Resko JA, Malley A, Begley D \& Hess DL 1973 Radioimmunoassay of testosterone during fetal development of the rhesus monkey. Endocrinology 93 156-161.

Said SI \& Mutt V 1970 Polypeptide with broad biological activity: isolation from small intestine. Science 169 1217-1218.

Said SI \& Rosenberg RN 1976 Vasoactive intestinal polypeptide: abundant immunoreactivity in neural cell lines and normal nervous tissue. Science $\mathbf{1 9 2}$ 907-908.

Sawangjaroen K, Anderson ST \& Curlewis JD 1997 Effects of pituitary adenylate cyclase-activating polypeptide (PACAP) and vasoactive intestinal polypeptide (VIP) on hormone secretion from sheep pituitary cells in vitro. Journal of Neuroendocrinology 9 279-286.

Simoni M, Weinbauer GF, Gromoll J \& Nieschlag E 1999 Role of FSH in male gonadal function. Annales d'Endocrinologie 60 102-106.

Stocco DM 2001 StAR protein and the regulation of steroid hormone biosynthesis. Annual Review of Physiology 63 193-213. 
Suburo AM, Chiocchio SR, Soler MV, Nieponice A \& Tramezzani JH 2002 Peptidergic innervation of blood vessels and interstitial cells in the testis of the cat. Journal of Andrology 23 121-134.

Suh JK, Mun KH, Cho CK, Shin HC, Kim YS \& Park TC 1995 Effect of vasoactive intestinal peptide and acetylcholine on penile erection in the rat in vivo. International Journal of Impotence Research 7 111-118.

Vaudry D, Gonzalez BJ, Basille M, Yon L, Fournier A \& Vaudry H 2000 Pituitary adenylate cyclase-activating polypeptide and its receptors: from structure to functions. Pharmacological Reviews 52 269-324.

Waschek JA 1995 Vasoactive intestinal peptide: an important trophic factor and developmental regulator? Developmental Neuroscience 17 1-7.
Zhang FP, Pakarainen T, Poutanen M, Toppari J \& Huhtaniemi I 2003 The low gonadotropin-independent constitutive production of testicular testosterone is sufficient to maintain spermatogenesis. PNAS $\mathbf{1 0 0}$ 13692-13697.

Received in final form 4 March 2007

Accepted 28 March 2007

Made available online as an Accepted Preprint 11 April 2007 